\title{
Hypermedia Learning and Prior Knowledge: Domain Expertise vs. System Expertise
}

\begin{abstract}
Prior knowledge is often argued to be an important determinant in hypermedia learning, and may be thought of as including two important elements: domain expertise and system expertise. However, there has been a lack of research considering these issues together. In an attempt to address this shortcoming, this paper presents a study that examines how domain expertise and system expertise influence students’ learning performance in, and perceptions of, a hypermedia system. The results indicate that participants with lower domain knowledge show a greater improvement in their learning performance than those with higher domain knowledge. Furthermore, those who enjoy using the Web more are likely to have positive perceptions of non-linear interaction. Discussions on how to accommodate the different needs of students with varying levels of prior knowledge are provided based on the results.
\end{abstract}

\section{Keywords:}

Hypermedia Learning, Individual Differences, Domain Knowledge, System Experience 


\section{Introduction}

In the past decade, the approaches embodied by learning technologies have shifted from a behaviourist to a constructivist perspective, in which students need to actively construct their understanding of subject matter (Littlejohn, 2002). Hypermedia is one of these technologies. Unlike the linear structure of books and traditional computer-assisted learning, hypermedia presents information with non-linear format (Khalifa and Lam, 2002). As suggested by Crook (1994), the format of information and the medium used to present information have considerable impact on learning. The hypermedia format supports a more flexible approach to instruction that helps students work with that content from several different perspectives (Spiro, et al., 1992). In other words, students are allowed to learn in their own ways - to make their own paths through the material available (Barua, 2001) - and to learn things at their own pace (Chen, 2002).

However, with this increase in flexibility and freedom for the individual come potential problems for some students. Hypermedia forces the students to decide their own navigation strategies. Students who lack the skills of independent study may feel confused because they are used to following their tutors' instruction and may find it difficult to decide their own learning paths (Ford and Chen, 2000; Last et al., 2001). For example, they may forget what they have already covered and run the risk of missing out important information (Chen and Angelies, 2003; McDonald and Stevenson, 1998a).

This suggests that not all types of student appreciate the flexibility and freedom offered by hypermedia systems and that the individual differences of students are therefore important factors to be considered in the development of hypermedia learning systems. 
Research into individual differences in hypermedia learning has highlighted a number of attributes where individuals may differ, which may affect the way in which they learn from and interact with hypermedia systems. These range from gender differences (e.g., Schumacher and Morahan-Martin, 2001), through cognitive styles (e.g., Kim, 2001; Chen and Macredie, 2004), to prior knowledge (Last et al., 2001; Holscher and Strube, 2000). Among these attributes, prior knowledge has particularly been recognised as an important attribute because it can influence how learners select information to place in memory and link new information to that already stored in memory (Spyridakis and Isakson, 1991). However, current research lacks a full understanding of how these are related to hypermedia learning. Few studies consider both learners' domain knowledge and system experience, both of which are aspects of prior knowledge that are relevant to learning using hypermedia systems. To address this gap, the study reported in this paper aims to examine the influence of both domain knowledge and system experience on users' learning performance and perception of a hypermedia tutorial. It was hoped that by assessing individuals' learning experiences a greater understanding of the role of domain knowledge and system experience in hypermedia learning could be reached.

This paper begins by building the theoretical background in order to understand the factors that have significant effects on student learning in hypermedia systems. It then progresses to discuss the current empirical study, which examines how individual differences, particularly focusing on the differences of system experience and prior domain knowledge, influence the students' learning experiences in a hypermedia tutorial. Finally, the findings of this study are discussed by comparing with those of previous work and illustrating the implications for the design of hypermedia learning systems. 


\section{Theoretical Background}

\subsection{Hypermedia Learning}

Hypermedia learning systems present course material in a non-linear structure, allow learners to control their learning pace, and offer numerous types of navigation support (Chen and Macredie, 2002). These features make hypermedia a useful learning technology, offering advantages over traditional didactic learning methods (Khalifa and Lam, 2002) and linear multimedia tutorials (Barua, 2001). In terms of non-linear structure, students are provided with freedom of navigation, giving them opportunities to select what information to access as well as how to sequence the information in a manner that is meaningful to them (Lawless and Brown, 1997). In this way, learners can construct their own individualised knowledge structures by cross-referencing the related topics in the subject domain. It has even been claimed that the flexibility that hypermedia offers in both structure and style may make it the "most effective technology system to date for individualizing instruction” (Jonassen, 1988, p.14).

With regard to learner control, students are given control over the learning strategy (Large, 1996). Hypermedia relies on learner control to be effective, since it is the student who determines which nodes to visit. This differs from lectures, for example, which are tutor-driven (Khafifa and Lam, 2002). Three types of learner control can be provided by hypermedia learning: (a) pace control - enabling the student to select the pace of work; (b) sequence control - allowing the student to decide the order in which to tackle lesson components; and (c) content control - pertaining to the kind of material and to the depth at which the material should be studied (Jarvey and Cote, 1999). 
Navigation support is a critical design issue in hypermedia learning systems (Bateman and Harvey, 1998; Rogers and Erickson, 1998). In respect of this issue, hypermedia environments provide various support for learners to structure their navigation strategies, including advanced organizers (Shapiro, 1999), graphical overviews (de Jong and van der Hulst, 2002) and structural cues (Nilsson and Mayer, 2002; Hsu and Schwen, 2003).

These features may make hypermedia able to provide a rich learning environment. However, these same features can also cause problems for some students because they may feel overwhelmed with too many choices. For example, they may be bombarded with non-linear structure and not know where to navigate next (Nielsen, 2000). Therefore, the value of hypermedia learning depends on each individual and an understanding of learners’ individual differences arguably becomes an important consideration in hypermedia learning. In particular, many studies have found that learners with different levels of prior knowledge benefit differently from hypermedia learning systems, with experts and novices showing different perceptions to the use of hypermedia learning systems and requiring different levels of navigational support (Shin et al., 1994; McDonald and Stevenson, 1998a, 1998b; Calisir and Gurel, 2003). In other words, prior knowledge can determine how a learner acquires information from hypermedia and influence his/her learning effectiveness in hypermedia systems (Alexander et al., 1994; Last et al., 2001). Learners’ prior knowledge includes levels of computing skills appropriate to the system, (i.e. system experience) and existing understanding of the content area (i.e. domain knowledge). The former refers to the users' knowledge of the system being used, including the general computing experience and experience using hypermedia and the Web; the latter refers to users' understanding of the content of the material presented in the hypermedia system (Lazonder, 2000). 
Previous studies have indicated that both have an impact on hypermedia learning, which will be discussed in the following sections.

\subsection{System Experience}

In the past few years, several studies have examined the impact of system experience on hypermedia learning. Among the various variables explained in previous studies, navigation performance and navigation behaviour are the main issues discussed in previous works. In terms of navigation performance, a study by Ford and Chen (2000) looked at the effect of individual differences on users' navigation behaviours and learning performance when using an educational hypermedia system. They found users with higher system experience could browse more pages and could reach more detailed levels of the subject content than those with lower levels of system experience.

Furthermore, Torkzadeh and Van Dyke (2002) examined the change in users’ Internet self-efficacy between before and after their computer training, with the results of their study indicating that computer training significantly improved Internet self-efficacy. In other words, when the users transfer from low experience to high experience, their Internet self-efficacy will be increased.

In addition, Lazonder et al. (2000) investigated the differences between novices and experts in searching for information on the Web. 25 fourth-grade students were divided into novice and expert classes on the basis of self-reported Web experience and a proficiency test. They found that experts performed significantly faster and better on searches for sites using a search engine than did novices. Other studies also found similar results, including Fidel et al. (1999) and Hill and Hannafin (1997). In general, these studies suggest that users with more system experience have more efficient navigation 
strategies than users with less experience. However, a study conducted by Fitzgerald and Semrau (1998) obtained contradictory results. They compared the process and outcomes of novice and expert teachers in a hypermedia-based learning program, which allowed students non-linear learning and free access to information. The results of this study revealed that novice teachers outperformed experts, leading Fitzgerald and Semrau (1998) to conclude that the users' performance will be not only dependent on the user but the particular system being used.

With regard to navigation behaviours, numerous studies have shown that learners with differing degrees of system experience have been shown differentially to prefer linear and non-linear pathways through a hypermedia program. For example, Reed and Oughton (1998) found that a low level of system experience had been linked to a preference for linear pathways through a hypermedia program, while a high level of system experience had been correlated with the choice of non-linear pathways. Moreover, Pazzani (1991) also demonstrated the importance of system experience in hypermedia learning, finding that experts profited most from a flexible path, whereas novices benefited most from a more structured path. This result is consistent with the study by Gerdes (1997), which found that a linear structure is more suitable for novices.

In addition to linear and non-linear paths, studies have also found that system experience influences the choice of navigation strategy. Farrell and Moore (2001) investigated whether the use of different navigation tools (linear, main menu and search engine) influenced users' achievement and attitude. The results indicated a significant difference for experts using the search engine. Other studies have also shown that experts are more likely to make use of advanced search options, such as Boolean operators (Holscher and 
Strube, 2000) and “jump” tools (e.g. Go, History, and Bookmark) (Kim, 2001). Novices, on the other hand, tend to be less flexible in their navigation strategies (Hill and Hannafin, 1997; Vassileva, 1996), and often return to previous stages of their search rather than attempt to use different strategies (Holscher and Strube, 2000).

\subsection{Domain Knowledge}

As with system experience, domain knowledge of the subject content has been shown to have an important influence on hypermedia learning, both in terms of the differences exhibited in navigation behaviour and disorientation problems. In terms of navigation behaviour, several studies report superior performance of domain experts over domain novices, especially efficiency and effectiveness (Marchionini, 1995; Patel, Drury, and Shalin, 1998). Furthermore, domain knowledge has been found to positively correlate with the number of navigational moves and the level of depth explored in the subject hierarchy (Chen and Ford, 1998). Furthermore, individuals with a lower level of domain knowledge have been shown to use longer queries (the number of words used to search) than those with higher domain knowledge (Holscher and Strube, 2000). In addition, whilst both users with high and low levels of knowledge benefit from navigational aids, users with a lower level of domain knowledge tend to rely on navigational aids more than those with a higher level of domain knowledge (McDonald and Stevenson, 1998b).

In respect of disorientation problems, previous studies have found that learners' domain knowledge influences the degree of disorientation in hypermedia systems. Last et al. (2001) conducted a qualitative study of 12 undergraduates where the levels of students' prior domain knowledge were decided by identifying whether they had had prior exposure to the material. They found that students with high domain knowledge of the 
subject content were better able to navigate easily, remember where they had been, and decide how to get to where they wanted to go. These students reported more positive feelings about using the system than did the low domain knowledge students and seemed to suffer much less from frustration while performing their tasks. The students with low domain knowledge often suffered from disorientation, not knowing where they had been, or where they could go to find the information that they needed.

Another study by McDonald and Stevenson (1998a) examined the effects of domain knowledge on hypermedia navigation and showed that subjects who lacked sufficient domain knowledge of the text topic demonstrated more disorientation problems than subjects with high domain knowledge. Non-knowledgeable learners tended to open more additional notes, which indicated that they could not remember where they had been and had problems in finding the information that they required. The studies described above are consistent in suggesting that non-knowledgeable users experience more disorientation problems in hypermedia learning. Compared with nonknowledgeable users, knowledgeable users may experience fewer disorientation problems in hypermedia because their deep levels of understanding of the subject matter enable them to impose structure on the hypermedia content (McDonald and Stevenson, 1998a). Mohageg (1992) asserted that knowledgeable users navigating in a hypermedia system might avoid disorientation because they already possess a mental representation of the concepts in the domain that they are searching. Therefore, there is a need to provide non-knowledgeable users with appropriate navigational support that reduces disorientation problems. 
In addition to the results of the aforementioned studies, which suggest that students with different levels of prior knowledge have different perceptions of hypermedia leaning, several studies have indicated that students performed better in learning environments of which they had more positive perceptions (Fullerton, 2000; Chen, 2002; Ghinea and Chen, 2003). Therefore, there is a need to conduct further studies to identify the perceptions of students possessing different levels of prior knowledge; the results of these studies might help to guide the development and evaluation of hypermedia learning systems. This paper presents such a study, which aims to examine the influence of system experience and domain knowledge on students’ learning performance and perception of a hypermedia tutorial, and subsequently discusses how to match relevant system attributes with the needs of knowledgeable and non-knowledgeable students.

\section{Research Design}

\subsection{Participants}

The participants in the study were 74 undergraduate students enrolled in an undergraduate Computer Science course at a university in London. All were taking the subject 'Computation and Algorithms' and they represented 37 percent of the students on the course. The students were each paid $£ 5$ for their participation and were further

motivated to take part in the experiment by being told that the tutorial might help them to learn the material associated with the subject. 


\subsection{Instruments}

\subsubsection{Hypermedia Tutorial}

A hypermedia tutorial was created containing material from the 'Computation and Algorithms' module. The tutorial included about 60 pages and the content was divided into six sections. Interface elements included: (a) a title bar located at the top of the screen showing the section name being viewed; (b) a control panel with the choices for menu, map, index, and the other available sections; and (c) the main body of the tutorial, providing referenced links and subject categories for selection. Figure 1 shows the screen design of this tutorial.

\section{\{Insert Figure 1\}}

The design of this tutorial was underpinned by considerations of non-linear interaction and learner control. The tutorial provided the students with rich links within the text, as well as a variety of navigation tools, including a map, an index, and a menu. In addition, each topic was further split into four subject categories, comprising: (a) overview; (b) pseudocode; (c) example; and (d) analysis. There were two types of overview, a general content overview and overviews for each specific topic. In this way, the students were given the freedom to decide their own learning paths and choose their favourite navigation tools and preferred content presentation so that their perceptions of non-linear interaction, navigation support, and content presentation could be identified by examining their replies to items in the questionnaire. 


\subsubsection{Questionnaires}

Two paper-based questionnaires were created. The first of these (Questionnaire 1) asked for background information, such as age, gender, and nationality. In particular, it was used to identify the students' levels of prior knowledge of the subject domain (i.e., the 'Computations and Algorithms' module), for example, how familiar they were with the module, how much they understand about this module from the lectures, and so on. It also asked about their system experience, and enjoyment of using computers, the Web, and Computer Aided Learning (CAL) programs, for example, how frequently they used computers and the Web and how much they enjoyed using the computers, the Web and the CAL. A five-point Likert scale was applied to identify users’ prior domain knowledge and system experience.

The second questionnaire (Questionnaire 2) asked the students about their perceptions of the hypermedia tutorial. According to the Theory of Reasoned Action (TRA) (Ajzen and Fishbein, 1975), which has been used widely to predict behaviour, perceptions are defined as perceived usefulness, perceived ease of use, preferences and willingness. On the basis of this theory, the questionnaire was designed to identify a wide range of user perceptions of the hypermedia tutorial, such as "subject content", "functionality and usability" and "navigation support". This meant that features of the system relevant to learner control, non-linearity, and navigation features could be assessed, allowing for a deeper analysis of any problems encountered by the participants. The relationships between the TRA and the questionnaire design are illustrated in Table 1.

\{Insert Tables 1 Here $\}$ 
The questionnaire included three open-ended questions and 42 closed statements to collect students' responses to the hypermedia tutorial. Of the 42 closed statements, 18 were positively phrased (e.g., "I found the suggested route through this tutorial helpful”) and 24 were negatively phrased (e.g., "I felt the structure of the tutorial was not clear”). In other words, the number of positively and negatively phrased questions was almost balanced, in an attempt to reduce bias in the questionnaire. All statements used a fivepoint Likert Scale consisting of: ‘strongly agree’; 'agree’; ‘neutral’; ‘disagree’; and ‘strongly disagree’. Students were required to indicate agreement or disagreement with each statement by placing a check mark at the response alternative that most closely reflected their opinion.

\subsubsection{Pre-Test and Post-Test}

The Pre-test and post-test were designed to assess the participants' level of knowledge of the subject domain both before and after using the hypermedia tutorial. Students were evaluated with a pre-test to examine their levels of prior knowledge of the subject domain and with a post-test to assess learning achievement. Both included 20 multiplechoice questions, each with four different answers and a “don’t know” option, from which the students could choose only one.

The questions were matched on the pre-test and post-test so that each question on the pre-test had a corresponding similar (but not the same) question on the post-test. Creating similar questions on the post-test was achieved by either re-writing the question (e.g., "Pseudocode usually doesn’t include:” re-written as “Which of the following would you commonly find in pseudocode:”) or, where appropriate, by substituting 
different numbers into the questions (e.g., "Using Quick sort on the following list of numbers, 3, 5, 2, 1, 6, the pivot would be?” re-written as “Using Quick sort on the following list of numbers, 4, 5, 7, 3, 1, the pivot would be?”).

\subsection{Procedure}

The experiment was carried out over a number of sessions during a three-week period in November 2002. Each student took part in one session only. Each session contained a group of students, each working individually. The procedure for the experiment was as follows:

1. On entering the room, the students were asked to sit in front of a computer and read a printed sheet of paper detailing the instructions for the experiment (what they would be asked to do, and for how long).

2. Students were then handed the first questionnaire (Questionnaire 1) to complete.

3. After completing the questionnaire, the students were given the pre-test to complete. The students were given a maximum of 15 minutes to complete the pre-test.

4. On completion of the pre-test, the students were asked to use the hypermedia tutorial to aid them in the learning of the module content. They were given a task sheet containing various exercises related to the content of the module. They were informed that completing this task sheet was optional and were allowed to use the hypermedia tutorial for a maximum of one hour.

5. After using the hypermedia tutorial, the students were given the post-test to complete. As with the pre-test, they were allowed a maximum of 15 minutes to complete this. 
6. Finally, after the post-test, the students were given another questionnaire (Questionnaire 2). On completion of the second questionnaire, the students were thanked for their participation and they left.

\subsection{Data Analysis}

A between-subjects design was used. The between-subjects factors were the students' prior system experience and domain knowledge. The dependent variables included learning performance and learning perceptions. The former was measured by a gain score, which was calculated as the post-test score minus the pre-test score. The latter was determined by the students' responses to the various questions about the tutorial from Questionnaire 2. All questionnaire responses, where appropriate, were scored as 5 for "strongly agree” through to 1 for "strongly disagree”. Two-way ANOVA was used to find the interaction effects of domain knowledge and system experience on students' learning performance and learning perceptions. Pearson correlations were carried out to find the relationships between pre-test score and gain score. A significance level of 0.05 was adopted.

\section{Results and Discussion}

\subsection{Measures of Prior Knowledge}

Two types of prior knowledge were considered in this study: domain expertise and system expertise. Both were measured with the questionnaire (see the section of questionnaires). To measure domain expertise, the students were asked how familiar they were with the module, how much they understand about the module from the lectures, and so on. To measure system expertise, the students were requested to say how much 
they enjoy using the web and computer-based learning packages, and how frequently they use the computers, and so on. The results of the two-way ANOVAs showed that there was no significant interaction between domain expertise and system expertise $(\mathrm{P}>0.05)$.

However, there was an interesting relationship between a subjective measure of domain expertise from the questionnaire and an objective measure of domain expertise from the pre-test score. In general, there was a consistency between these two measures. One example is that responses to the question, "How much have you understood about this module from your lectures?” had a significant interaction with pre-test performance $(\mathrm{P}<0.05)$. In addition, there was also a significant interaction between the question “How familiar are you with the contents of this module?” and the Pre-Test score $(\mathrm{P}<0.01)$. Those students who had a greater understanding from the lectures and had a higher familiarity with the module content obtained better scores from the Pre-Test. These findings reveal that the subjective measure from the questionnaire had the same value as the objective measure from the Pre-Test, and this conformance may offer the confidence and reliability in the other related findings from this study.

\subsection{Overall Learning Performance}

Table 2 presents data on the overall learning performance of the participants. The analysis of students’ overall learning performance indicates that the students’ Post-Test scores were positively related to pre-test scores $(\mathrm{P}<0.001)$. However, an unexpected finding, inconsistent with those of some previous studies (Ford and Chen, 2000; 2001), is that the gain score was found to be negatively correlated with pre-test performance 
$(\mathrm{P}<0.001)$. This shows that those who performed poorly on the pre-test were more likely to make a greater improvement on the post-test than those who performed relatively better on the pre-test.

The result suggests that those with a lower level of domain knowledge gained more benefit from this tutorial than those with an initially higher level of domain knowledge. This is probably because most of the content of the tutorial came from the lecture notes for the module. In other words, the tutorial works as a reinforcement of the lectures, which can help the non-knowledgeable students build a solid grounding by recalling what they have already learnt from the lecture. Conversely, the tutorial is less useful to the knowledgeable students, who may be seeking to learn additional new material that is not offered in the tutorial.

\section{\{Insert Table 2 Here $\}$}

These findings suggest that an effective hypermedia tutorial provide subject content that is suitable for both non-knowledgeable and knowledgeable students. The former need to enhance their understanding with the basic material included in the lectures, whereas the latter are interested in more advanced material excluded from the lectures. In addition, the hypermedia tutorial should allow the students to easily differentiate levels of subject content based on their prior knowledge. One of the possible approaches is to point out the actual level in the content with different background colours so that students can jump to the different levels by identifying the colours (Reuter, Doebner, and Moller, 1998). Another approach is to provide annotated links, which use pop-up windows to list the pre-requisite concepts. This approach can help students understand the role of a particular page and the relationships between items in the subject matter so that they can 
successfully find the appropriate and coherent paths (Lewis and Polson, 1990). A final approach is to present the subject content using hierarchical maps, which provide learners with structural cues between concepts, and can help learners to integrate their knowledge (Nilsson and Mayer, 2002). In particular, hierarchical maps can help novices to structure the material (Calisir and Gurel, 2003).

\subsection{Domain Knowledge and Content Presentation}

It seems that the levels of the students' domain knowledge of the subject content influence their perceptions of the content presentation. In analysing the participants' responses to the question of whether they would have liked there to be more examples, the result showed that the main effects of students' familiarity with the module was significant at $\mathrm{P}<0.05$. In addition, a significant main effect for considering the difficulties of the module was also found at $\mathrm{P}<0.01$. Table 3 shows the scales' Mean scores and Standard Deviation (SD). The students who had higher familiarity with, and low difficulties in relation to, the module did not need more examples. Conversely, the students who were not familiar with the module and found the module more difficult would have liked there to be more examples. One of the possible reasons is that examples represent the 'wholeness' of the content, which is beneficial to novice students who fail to integrate subject 'pieces' into a whole (Simmons and Lunetta, 1993). The other reason is that examples are down-to-earth material and demonstrate the subject content with practical information. In other words, the students can acquire knowledge in a realistic context. In this way, less effort is needed to integrate ideas and concepts and learner can immediately apply what they have learnt.

\{Insert Table 3 Here\} 
Another interesting finding was indicated in the question that asked whether the tutorial was easier to understand than a book. The main effect of familiarity with the module was also found to be significant at $\mathrm{P}<0.05$. The students with high familiarity with the module did not consider that the tutorial was easier to understand than a book (Table 3). This may be because these knowledgeable students need more advanced material beyond the lecture content covered by the tutorial. Therefore, they might think that the books could help them to broaden their understanding of the subject easily, and this suggests that the hypermedia tutorial should not only provide the content of the lecture material, but should also include the reading list. In addition, the reading list should be able to adapt to the students' knowledge level by using linking hiding (Ng, et al., 2002), with the number of documents shown based on the student's knowledge level. In other words, the knowledgeable students can be allowed to access a wide range of pertinent documents, whilst the less-knowledgeable students will be restricted to a subset of the available documents. This may help the less-knowledgeable students to reduce information overload.

\subsection{System Experience and Non-linear Interaction}

When analysing the students' responses to how they considered that the links could help them to understand relationships between topics and how they liked being able to choose topics according to their own needs, the results showed that there was a significant main effect $(\mathrm{P}<0.05)$ of enjoyment in using the Web. Table 4 shows the scales' mean scores and SD. This suggests that those who enjoy the Web are less likely to struggle with the non-linearity of hypermedia. Since favourable attitudes towards the Web are linked to familiarity with the Web (Liaw, 2002), those who enjoy using the Web use it more than 
those who experience less enjoyment, and they therefore are more familiar and more comfortable with the non-linearity.

\section{\{Insert Tables 4 Here}

On the other hand, in relation to questions of the tutorial's structure and navigational complexity (in terms of knowing which links corresponded to the information that the students wanted), the results indicated that those who enjoy using the Web less showed more negative responses. The main effect of enjoyment in using the Web was found to be significant at $\mathrm{P}<0.05$. The scales' mean scores and SD are presented in Table 4. Previous research suggests that individuals with a low level of system experience are more likely to have trouble with non-linear navigation, in terms of getting lost (Beishuizen et al., 1994) and becoming disorientated (Chen and Ford, 1998). If Web enjoyment is considered as an indicator of Web experience, then the findings from this experiment are consistent with these findings.

The findings of the aforementioned studies and current research raise a challenge in how to help novices enjoy non-linear learning and reduce their disorientation problems. One way to solve this problem is to provide structural aids that inform users of what information is available, as well as where it may be located and how it may be organised (Hsu and Schwen, 2003). In addition, a systematic visual overview that represents the basic and inherent structure of the domain can help them to develop a better route for the acquisition of the information in the subject domain (de Jong and van der Hulst, 2002). Other solutions include advice treatment to provide recommendation on the sequence to follow through the material (Shin et al., 1994) and advanced organizers to provide indications of the relationships between topics (Farrell and Moore, 2001). 


\section{Concluding Remarks}

Different users have different needs with regard to hypermedia learning. It is important to understand whether these needs are due to different experience with the system or to levels of knowledge. As suggested by Torkzadeh and Lee (2003), understanding users' prior knowledge can influence the system success directly and indirectly. The paper has followed this line to examine the relationships between prior knowledge and student learning in hypermedia systems. The main conclusions include: (a) the students with lower domain knowledge gain more benefits from the hypermedia tutorial than those with higher prior knowledge; (b) examples are useful vehicles for the students with low levels of domain knowledge; and (c) the students who enjoy the Web and web-based learning are more able to cope with the non-linear interaction. As these results suggest, some students may need greater support and guidance from instructors, while others may be able to follow hypermedia tutorials relatively independently. The results also suggest that students with different levels of prior knowledge have different perceptions of the features of the hypermedia tutorial, indicating the need to be aware of students' prior knowledge when planning for hypermedia tutorials in educational settings. Thus, instructors should not assume that every student will benefit equally from hypermedia learning in educational settings. There remains the need for guidance to ensure that all students can meet the learning objectives set by instructors. It is therefore important to consider versatility in system design to allow for use by a variety of individuals, rather than a particular user group.

This study has shown the importance of understanding the students' prior knowledge in the development of hypermedia tutorials, but it was only a small-scale study. Further 
studies need to be undertaken with a larger sample to provide additional evidence. The other direction for further work arising from this study is whether it is true that the Web enjoyment can be linked to system experience. In addition, there is a need for future research to examine why less-knowledgeable students made a greater improvement than knowledgeable students. This may, for example, have been because the lessknowledgeable students chose not to attend the lectures. It would also be interesting to compare the perceptions of students who attend the lectures with those of the students who do not attend. Gathering information on these issues through further work can help clarify the findings from the present study. Moreover, the findings of studies looking at these areas could be integrated to build robust learning models for the development of personalised hypermedia tutorials that can accommodate the needs of students with different levels of domain expertise and system expertise.

\section{Acknowledgements}

The authors are grateful for Professor Xiaohui Liu's help with this study and for the support of the EPSRC (Grant number: GR/R57737/01) for funding this project.

\section{References}

Ajzen, I \& Fishbein, M. (1975) Belief, Attitude, Intention and Behavior: An Introduction to Theory and Research. Reading, Mass: Addison-Wesley.

Alexander P. A, Kulikowich J. M. and Jetton T. L. (1994) The role of subject-mater knowledge and interest in the processing of linear and nonlinear texts. Review of Educational Research 64, 201-252

Barua S. (2001) An interactive multimedia system on "Computer Architecture, Organization, and Design”. IEEE Transactions on Education 44, 41-46. 
Bateman W. E. \& Harvey F. A. (1998) . Hypermedia navigation: Where do we go from here? Paper presented at the Association for Educational Communications and Technology, St. Louis.

Beishuizen J., Stoutjesdijk E., \& Van Putten K. (1994) Studying textbooks: effects of learning styles, study task and instruction. Learning and Instruction 4, 151-174.

Calisir F. \& Gurel Z. (2003) Influence of text structure and prior knowledge of the learner on reading comprehension, browsing and perceived control. Computers in Human Behavior 19, 135-145.

Chen S. Y \& Ford N (1998) Modelling user navigation behaviours in a hypermediabased learning system: an individual differences approach. International Journal of Knowledge Organization 25, 67-78.

Chen S. Y. \& Angelides M. C. (2003) Customisation of internet multimedia information systems design through user modelling, in: Architectural Issues of Web-Enabled Electronic Business, N.S. Shi and V.K. Murthy, Eds., Idea Group Publishing, Hearshey, Pennsylvania, 241-255.

Chen S. Y. \& Macredie R. D. (2004) Cognitive modelling of student learning in webbased instructional programmes. International Journal of Human-Computer Interaction 17, 375-402

Chen S.Y. \& Macredie R.D. (2002). Cognitive styles and hypermedia navigation: development of a learning model. Journal of the American Society for Information Science and Technology, 53, 1, 3-15.

Chen S.Y. (2002). A cognitive model for non-linear learning in hypermedia programmes. British Journal of Educational Technology 33, 449-460.

Crook C. (1994). Computers and the collaborative experience of learning. London: Routledge.

de Jong T. \& van der Hulst A. (2002) The effects of graphical overviews on knowledge acquisition in hypermedia. Journal of Computer Assisted Learning 18, 219-231.

Farrell, I. H. \& Moore, D.M. (2001) The effect of navigation tools on learners' achievement and attitude in a hypermedia environment. Journal of Educational Technology Systems, 29 169-181

Fidel R., Davies R. K., Douglass M.H., Holder J. K., Hopkins C. J., Kushner E. J., Miyagishima B. K., and Toney C. D. (1999). A visit to the information mall: web searching behavior of high school students. Journal of the American Society for Information Science 50, 1, 24-37.

Fitzgerald G. E. \& Semrau L.P. (1998). The effects of learner differences on usage patterns and learning outcomes with hypermedia case studies. Journal of Educational Multimedia and Hypermedia 7, 309-331. 
Ford N. \& Chen S. Y. (2000) Individual differences, hypermedia navigation and learning: an empirical study. Journal of Educational Multimedia and Hypermedia 9, 281-311

Ford N. \& Chen S. Y. (2001) Matching/mismatching revisited: an empirical study of learning and teaching styles. British Journal of Educational Technology 32, 522.

Fullerton, K. (2000) The interactive effects of field dependence-independence and Internet document manipulation style on student achievement from computerbased Instruction. Ed.D Dissertation. University of Pittsburgh.

Gerdes H. (1997) Learn with text and hypermedia, Pabst, Lengerich.

Ghinea G. \& Chen S. Y. (2003) The impact of cognitive styles on perceptual distributed multimedia quality. British Journal of Educational Technology. 34, 393-406.

Hill J.R. \& Hannafin M.J. (1997). Cognitive strategies and learning from the World Wide Web. Educational Technology Research and Development 45, 37-64.

Holscher C., \& Strube G. (2000). Web search behavior of Internet experts and newbies. Computer Networks 33 337-346.

Hsu, Y. and Schwen, T. (2003) The effects of structural cues from multiple metaphors on computer users' information search performance. International Journal of Human-Computer Studies 58, 39-55.

Jarvey, D. and Cote, D. (1999) The Development of an Instructional Simulation on the World Wide Web [http://home.istar.ca/ dicote/projects/ paper.htm, accessed February 2001].

Jonassen D. H. (1988). Designing structured hypertext, and structuring access to hypertext. Educational Technology 28, 13-16.

Khalifa M. \& Lam R. (2002). Web-based learning: effects on learning process and outcome. IEEE Transactions on Education, 45, 350-356.

Kim, K. (2001) Implications of user characteristics in information seeking on the world wide web. International Journal of Human-Computer Interaction, 13, 323-340.

Large A. (1996) Hypertext instructional programs and learner control: a research review. Education for Information, 4, 95- 106.

Last D. A., O'Donnell A. M. \& Kelly A. E. (2001) The Effects of Prior Knowledge and Goal Strength on the use of Hypermedia. Journal of Educational Multimedia and Hypermedia 10, 3-25.

Lawless K. A. \& Brown S. W. (1997) Multimedia learning environments: issues of learner control and navigation. Instructional Science 25, 117-31. 
Lazonder A. W., Biemans H. J. A. \& Wopereis I. G.. (2000) Differences between novice and experienced users in searching information on the world wide web Journal of the American Socienty for Information Science and Technology, 51, 576-581.

Lazonder A.W. (2000) Exploring novice users' training needs in searching information on the WWW. Journal of Computer Assisted Learning, 16, 326-335.

Lewis C. and Polson P. G. (1990) Theory-based design for easily learned interfaces. HCI, 5, 191-220.

Liaw S. S. (2002) An Internet survey for perceptions of computers and the World Wide Web: relationship, prediction, and difference. Computers in Human Behavior, 18, 17-35.

Littlejohn, A. (2002) New lessons from past experiences: recommendations for improving continuing professional development in the use of ICT. Journal of Computer Assisted Learning 18, 166-174

Marchionini, G. (1995). Information Seeking in Electronic Environments. Cambridge University Press.

McDonald S., and Stevenson R.J. (1998a). The effects of text structure and prior knowledge of the learner on navigation in hypertext. Human Factors, 40, 18 -27.

McDonald S., and Stevenson R.J. (1998b). Navigation in hyperspace: an evaluation of the effects of navigational tools and subject matter expertise on browsing and information retrieval in hypertext. Interacting with Computers, 10, 129-142.

Mohageg M. F. (1992) The influence of hypermedia linking structures on the efficiency of information retrieval. Human Factors, 34, 351-367.

Ng M., Maier P., Armstrong R. \& Hall W. (2002). Making Web-Based Learning Adaptive. Proceedings of the ED-MEDIA 2002, World Conference on Educational Multimedia, Hypermedia \& Telecommunication, Denver, Colorado, USA June 24-29, 2002

Nielsen, J. (2000). Designing Web usability: The practice of simplicity. Indianapolis, IN: New Riders.

Nilsson R.M., and Mayer R.E. (2002). The effects of graphic organizers giving cues to the structure of a hypertext document on users' navigation strategies and performance. International Journal of Human-Computer Studies 57, 1-26.

Patel, S.C., Drury, C.G., \& Shalin, V.L. (1998). Effectiveness of expert semantic knowledge as a navigational aid within hypertext. Behavior and Information Technology, 17, 313-324.

Pazzani M. J. (1991) Influence of prior knowledge on concept acquisition: Experimental and computational results Journal of Experimental Psychology: Learning, Memory, and Cognition, 17, 416-432. 
Reed W.M., \& Oughton J.M. (1998). The effects of hypermedia knowledge and learning style on the construction of group concept maps. Computers in Human Behavior, 14, 1-22.

Reuter, M., Doebner D., and Moller D.P.F. (1998) First experiences with ergonomiccognitive structures for the WWW-presentation of the University of Clausthal. 6th European Congress on Intelligent Techniques and Soft Computing. EUFIT '98 vol.2 p.1141-1146, Aachen (Germany): Verlag Mainz.

Rogers, P., and Erickson, M. (1998). Layers of navigation: hypermedia design for an illstructured domain. Paper presented at the annual meeting of the Association for Educational Communications and Technology, St. Louis.

Schumacher, P. \& Morahan-Martin, J. (2001). Gender, Internet and computer attitudes and experiences. Computers in Human Behavior 17, 95-110.

Shapiro A. M. (1999) The relationship between prior knowledge and interactive overviews during hypermedia-aided learning. Journal of Educational Computing Research 20,143-167.

Shin C.E., Schallert D.L., and Savenye W.C. (1994). Effects of learner control, advisement, and prior knowledge on young students' learning in a hypertext environment. Educational Technology Research and Development, 42, 33-46.

Simmons P. E., and Lunetta V.N. (1993). Problem-solving behaviors during a genetics computer simulation: beyond the expert/novice dichotomy. Journal of Research in Science Teaching 30, 2, 153-173.

Spiro, R. J., Feltovich, P. J., Jacobson, M. J., \& Coulson, R. L. (1992). Cognitive flexibility, constructivism, and hypertext: Random access instruction for advanced knowledge acquisition in ill-structured domains. In T. M. Duffy \& D. H. Jonassen (Eds.), Constructivism and the technology of instruction: A conversation (pp. 57-76). Hillsdale, NJ: Lawerence Erlbaum Associates

Spyridakis J. H., and Isakson C. S. (1991). Hypertext: a new tool and its effect on audience comprehension. IEEE-IPCC, p. 37-44.

Torkzadeh G., \& Van Dyke, T.P. (2002). Effects of training on Internet self-efficacy and computer user attitudes. Computers in Human Behavior, 18, 479-494.

Torkzadeh, G. and Lee, J. (2003) Measures of perceived end-user computing skills. Information \& Management. 40, 607-615.

Vassileva J. (1996). A task-centered approach for user modelling in a hypermedia office documentation system. User Modeling and User-Adapted Interaction, 6, 185224. 
Figure 1 Screen Design of the hypermedia tutorial

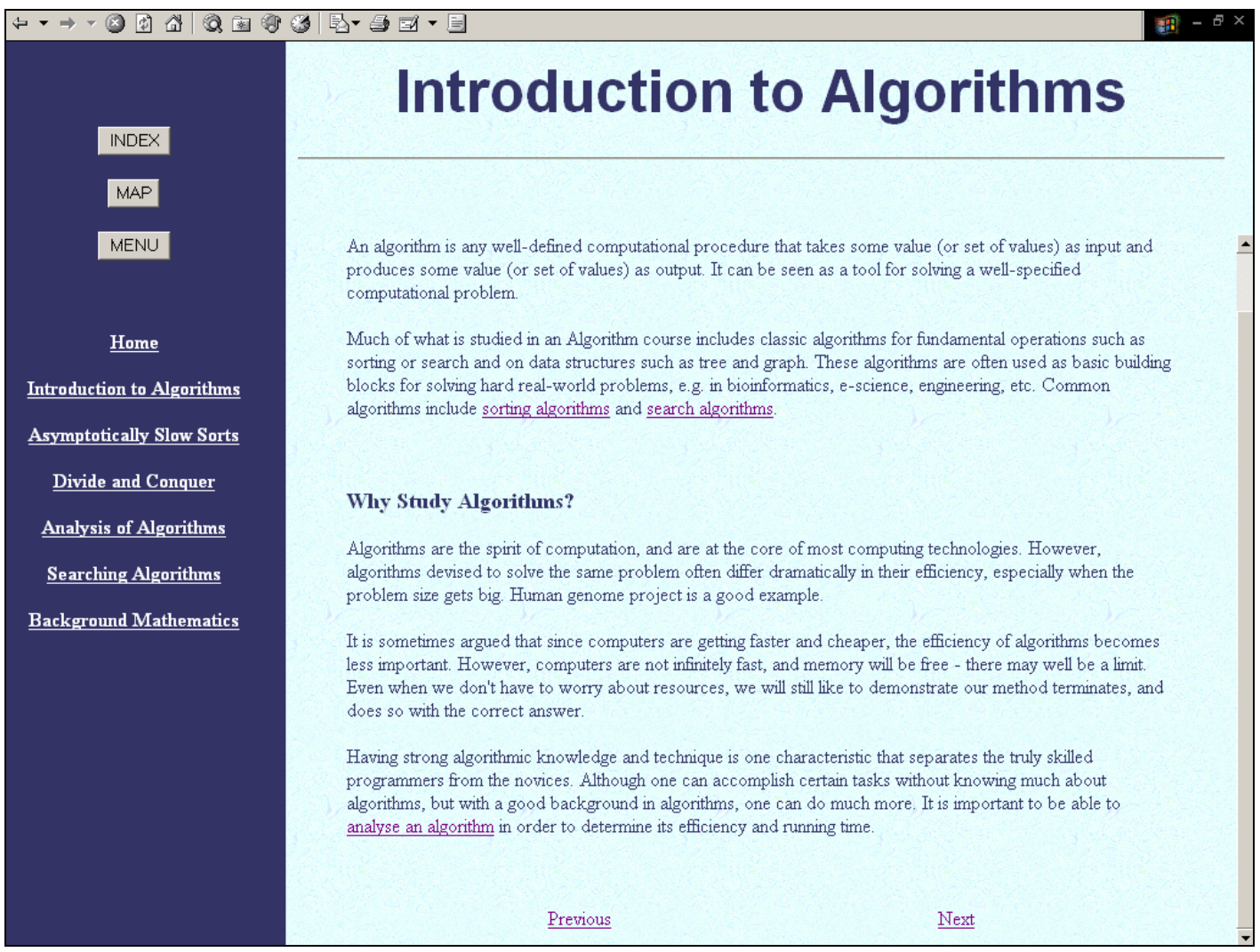

Table 1: TRA and Questionnaire Design

\begin{tabular}{|l|l|l|}
\hline $\begin{array}{l}\text { Dimensions of Perceptions } \\
\text { from TRA }\end{array}$ & $\begin{array}{l}\text { Areas in } \\
\text { Questionnaire }\end{array}$ & $\begin{array}{l}\text { Examples of Closed Statements from } \\
\text { Questionnaire }\end{array}$ \\
\hline Perceived usefulness & $\begin{array}{l}\text { General } \\
\text { Perceptions }\end{array}$ & $\begin{array}{l}\text { The tutorial is only useful for students who } \\
\text { are already familiar with algorithms. }\end{array}$ \\
\cline { 3 - 3 } & $\begin{array}{l}\text { This tutorial covers computation and } \\
\text { algorithms very well. }\end{array}$ \\
\hline \hline \multirow{2}{*}{ Perceived ease of use } & Navigation Support & $\begin{array}{l}\text { I found it easy to get lost using this } \\
\text { tutorial. }\end{array}$ \\
\cline { 3 - 3 } & & $\begin{array}{l}\text { It was difficult to know which links } \\
\text { corresponded to the information I wanted. }\end{array}$ \\
\hline \hline \multirow{2}{*}{ Willingness } & Functionality and & $\begin{array}{l}\text { I would like to learn from a human tutor } \\
\text { rather than from this tutorial. }\end{array}$ \\
\cline { 3 - 4 } & Usability & $\begin{array}{l}\text { It is much easier to understand algorithms } \\
\text { by using this tutorial than by reading a } \\
\text { book, because it is interactive. }\end{array}$ \\
\hline \hline \multirow{2}{*}{ Preferences } & Subject Content & $\begin{array}{l}\text { I would have liked there to be more } \\
\text { examples. }\end{array}$ \\
\cline { 2 - 3 } & $\begin{array}{l}\text { Presentation } \\
\text { Layout }\end{array}$ & $\begin{array}{l}\text { I did not like the colours used for this } \\
\text { tutorial. }\end{array}$ \\
\hline
\end{tabular}


Table 2: Overall Learning Performance

\begin{tabular}{|l|r|r|r|r|}
\hline & Minimum & Maximum & \multicolumn{1}{c|}{ Mean } & \multicolumn{1}{l|}{ SD } \\
\hline Score of Pre-test & 2.00 & 18.00 & 8.43 & 3.62 \\
\hline Score of Post-test & 1.00 & 18.00 & 9.41 & 3.87 \\
\hline Gain Score & -6.00 & 6.00 & .97 & 2.94 \\
\hline
\end{tabular}

Table 3: Domain Knowledge and Content Presentation

\begin{tabular}{|l|r|r|r|r|r|}
\hline Whether they would have liked there to be more examples \\
\hline $\begin{array}{l}\text { Familiarities with } \\
\text { the module }\end{array}$ & Not at All & Not Much & Neutral & Quite a Lot & Very Much \\
\hline Mean & 4.02 & 3.30 & 3.00 & 2.71 & 2.09 \\
\hline SD & .527 & .823 & .816 & .539 & .455 \\
\hline $\begin{array}{l}\text { The difficulties of } \\
\text { the module }\end{array}$ & Not at All & Not Much & Neutral & Quite a Lot & Very Much \\
\hline Mean & 3.09 & 3.26 & 3.50 & 3.91 & 4.33 \\
\hline SD & .527 & .656 & .701 & .578 & .816 \\
\hline Whether the tutorial was easier to understand than a book \\
\hline $\begin{array}{l}\text { Familiarities with } \\
\text { the module }\end{array}$ & Not at All & Not Much & Neutral & Quite a Lot & Very Much \\
\hline Mean & 3.20 & 2.36 & 2.04 & 1.67 & 1.55 \\
\hline SD & .398 & .505 & .940 & .816 & .552 \\
\hline
\end{tabular}

Table 4: System Experience and Non-linear Interaction

\begin{tabular}{|c|c|c|c|c|c|c|}
\hline \multirow{2}{*}{\multicolumn{2}{|c|}{$\begin{array}{l}\text { Statements of the } \\
\text { Questionnaire }\end{array}$}} & \multicolumn{5}{|c|}{ Enjoyment in Using the Web } \\
\hline & & Not at All & Not Much & Neutral & Quite a Lot & Very Much \\
\hline \multirow{3}{*}{$\begin{array}{l}\text { Links could help them } \\
\text { understand relationships } \\
\text { between topics. }\end{array}$} & Mean & 2.10 & 2.59 & 2.91 & 3.17 & 3.82 \\
\hline & SD & .449 & .888 & .539 & .983 & .874 \\
\hline & & & & & & \\
\hline \multirow{3}{*}{$\begin{array}{l}\text { They could choose topics } \\
\text { according to their own } \\
\text { needs. }\end{array}$} & Mean & 1.50 & 2.09 & 2.18 & 2.41 & 3.20 \\
\hline & SD & .548 & .944 & .751 & .152 & .398 \\
\hline & & & & & & \\
\hline \multirow{2}{*}{$\begin{array}{l}\text { The structure of the } \\
\text { tutorial was not clear. }\end{array}$} & Mean & 4.00 & 3.63 & 3.19 & 2.89 & 2.30 \\
\hline & SD & .414 & .169 & .681 & .701 & .160 \\
\hline \multirow{2}{*}{$\begin{array}{l}\text { It was difficult to know } \\
\text { which links corresponded to } \\
\text { information they wanted. }\end{array}$} & Mean & 4.01 & 3.69 & 3.30 & 3.03 & 2.00 \\
\hline & SD & .160 & .823 & .539 & .030 & .183 \\
\hline
\end{tabular}

